\title{
Hybrids of Cinchona Alkaloids and Bile Acids as Antiparasitic Agents Against Trypanosoma cruzi
}

\author{
Daniel Musikant ${ }^{1}$, Aurélie Leverrier ${ }^{2,3}$, Diana Bernal ${ }^{1}$, Gabriel Ferri ${ }^{4}$, Jorge A. Palermo ${ }^{2,3}$ and \\ Martin M. Edreira 1,4,5,*(D) \\ 1 Departamento de Química Biológica, Facultad de Ciencias Exactas y Naturales, Universidad de Buenos \\ Aires, 1428 Ciudad deBuenos Aires, Argentina \\ 2 Departamento de Química Orgánica, Facultad de Ciencias Exactas y Naturales, Universidad de Buenos \\ Aires, 1428 Ciudad de Buenos Aires, Argentina \\ 3 CONICET-Universidad de Buenos Aires, Unidad de Microanálisis y Métodos Físicos en Química \\ Orgánica (UMYMFOR), 1428 Ciudad de Buenos Aires, Argentina \\ 4 CONICET-Universidad de Buenos Aires, Instituto de Química Biológica de la Facultad de Ciencias Exactas y \\ Naturales (IQUIBICEN), 1428 Ciudad de Buenos Aires, Argentina \\ 5 Department of Pharmacology and Chemical Biology, School of Medicine, University of Pittsburgh, \\ Pittsburgh, PA 15213, USA \\ * Correspondence: mme2@pitt.edu; Tel.: +54-11-5285-8412
}

Received: 27 June 2019; Accepted: 13 July 2019; Published: 30 August 2019

check for updates

\begin{abstract}
The current chemotherapy of Chagas disease needs to be urgently improved. With this aim, a series of 16 hybrids of Cinchona alkaloids and bile acids were prepared by functionalization at position C-2 of the quinoline nucleus by a radical attack of a norcholane substituent via a Barton-Zard decarboxylation reaction. The antitrypanosomal activity of the hybrids was tested on different stages and strains of T. cruzi. In particular, eight out of 16 hybrids presented an $\mathrm{IC}_{50} \leq 1 \mu \mathrm{g} / \mathrm{mL}$ against trypomastigotes of the CL Brener strain and/or a selectivity index higher than 10 . These promising hybrids yielded similar results when tested on trypomastigotes from the RA strain of T. cruzi (discrete typing unit-DTU-VI). Surprisingly, trypomastigotes of the Y strain (DTU II) were more resistant to benznidazole and to most of the hybrids than those of the CL Brener and RA strains. However, the peracetylated and non-acetylated forms of the cinchonine/chenodeoxycholic bile acid conjugate $\mathbf{4 f}$ and $\mathbf{5 f}$ were the most trypanocidal hybrids against $\mathrm{Y}$ strain trypomastigotes, with $\mathrm{IC}_{50}$ values of 0.5 and $0.65 \mu \mathrm{g} / \mathrm{mL}$, respectively. More importantly, promising results were observed in invasion assays using the $\mathrm{Y}$ strain, where hybrids $\mathbf{5 f}$ and $\mathbf{4 f}$ induced a significant reduction in intracellular amastigotes and on the release of trypomastigotes from infected cells.
\end{abstract}

Keywords: Cinchona alkaloids; bile acids; hybrids; Trypanosoma cruzi; amastigotes; antiparasitic activity

\section{Introduction}

The current pharmacological treatment (i.e., benznidazole (Bz) and nifurtimox (Nf)) against Trypanosoma cruzi, the etiological agent of Chagas disease, are highly toxic and not effective, especially during the chronic stage of the disease. In order to find alternative treatments against the disease, numerous studies have shown that quinoline derivatives display cytotoxic activity against different protozoan parasites [1-6]. A unique class of quinoline alkaloids are the Cinchona cinchona alkaloids, which includes quinine, quinidine, cinchonidine, and cinchonine. These naturally occurring compounds have all shown some degree of anti-parasitic activity, especially against Plasmodium falciparum. In particular, quinidine is the most active antiprotozoal alkaloid of this family and has been used for more than 400 years for the treatment of malaria [7]. 
With the strategy of combining the anti-parasitic properties of natural Cinchona alkaloids [8] with the known properties of bile acids as drug transporters [9], a series of 16 hybrids of Cinchona alkaloids and bile acids were prepared via a Barton-Zard decarboxylation reaction [10] (Table 1). Briefly, quinine, quinidine, cinchonine and cinchonidine were functionalized at position C-2 of the quinoline nucleus by a radical attack of a norcholane substituent. All the hybrids showed antiplasmodial activity $\left(\mathrm{IC}_{50} \leq 6 \mu \mathrm{g} / \mathrm{mL}\right)$, particularly those containing a nor-chenodeoxycholane moiety $(\mathbf{4 b}, \mathbf{4 d}, 4 \mathrm{f}, 4 \mathbf{h}, 5 \mathbf{b}$, $\mathbf{5 d}, \mathbf{5 f}, \mathbf{5 h}$ ) with $\mathrm{IC}_{50}$ values comparable to those of the natural alkaloids and selectivity indices in the range of 5.6-15.7 [10]. In addition, seven compounds (4d, $4 \mathbf{f}, \mathbf{4 h}, \mathbf{5 b}, \mathbf{5 d}, \mathbf{5 f}, \mathbf{5 h})$ showed promising trypanocidal activity against $T$. brucei, with $\mathrm{IC}_{50}$ values in the same range as the commercial drug suramin [10]. These results prompted us to evaluate the anti-trypanosomal activity of the hybrids against different strains and stages of Trypanosoma cruzi.

Table 1. Hybrids of Cinchona alkaloids and bile acids were prepared via a Barton-Zard decarboxylation reaction.

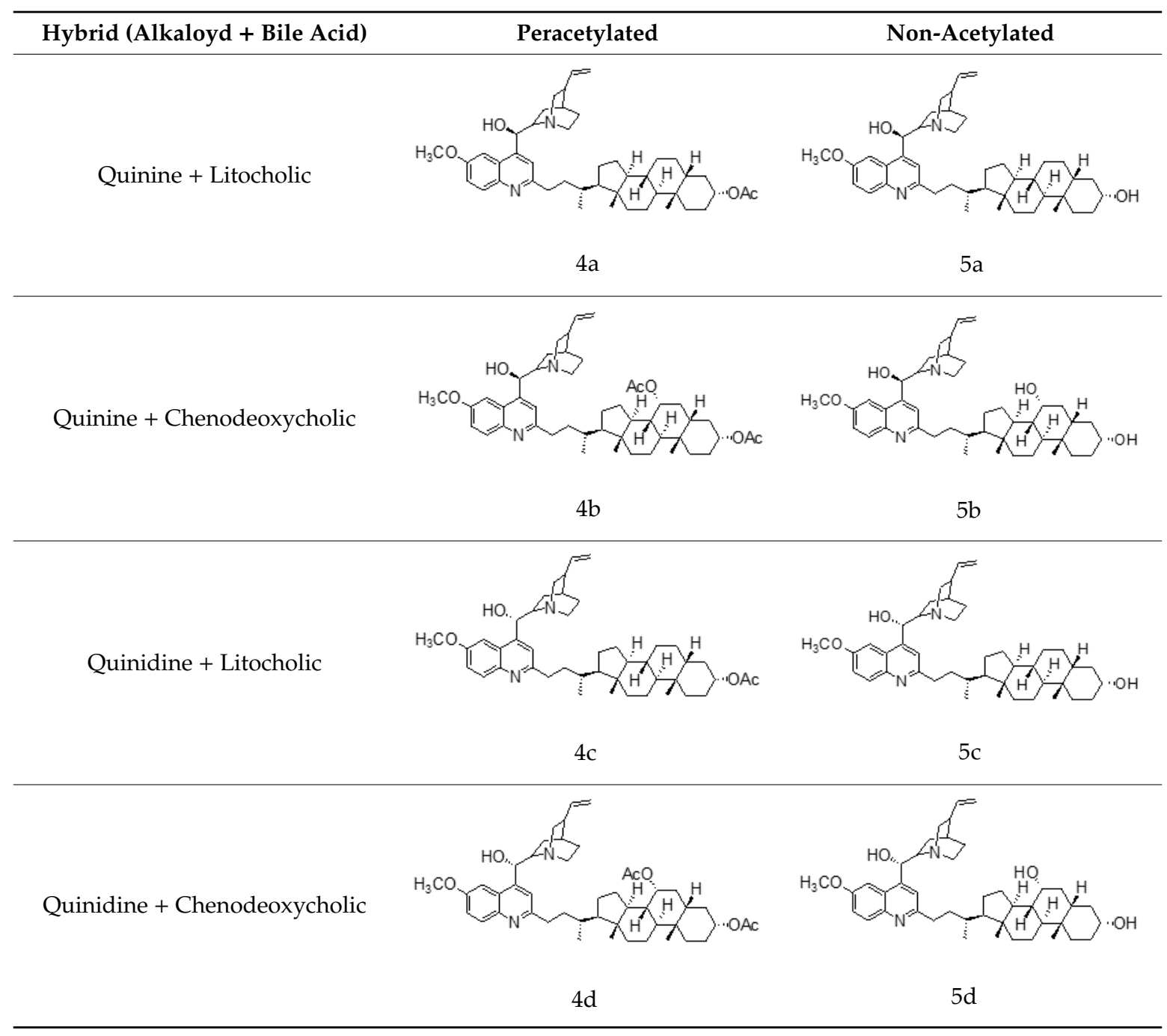


Table 1. Cont.

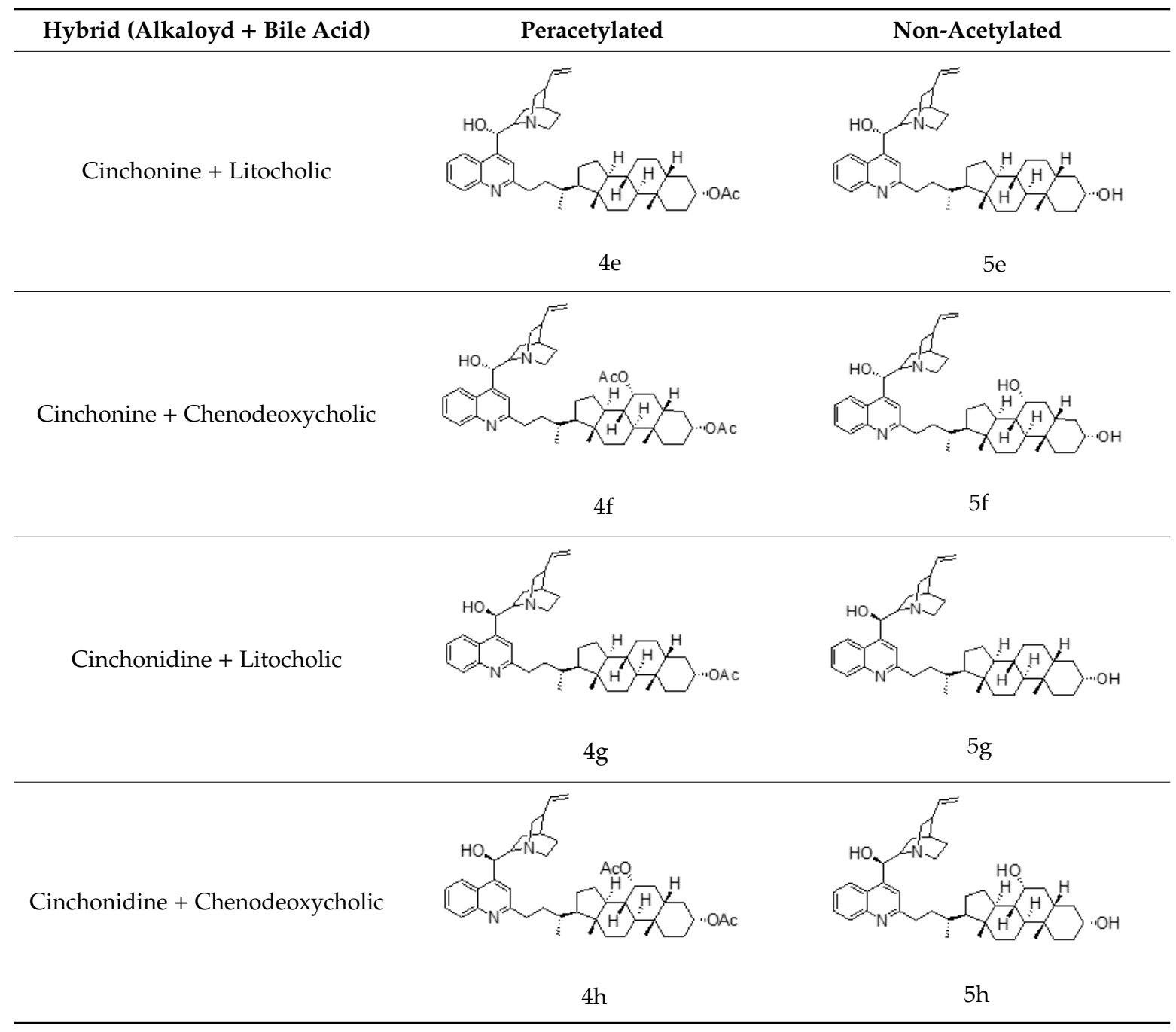

\section{Results}

A series of 16 hybrids of Cinchona alkaloids and bile acids were prepared via a Barton-Zard decarboxylation reaction, as previously described [10]. With the aim of evaluating the anti-trypanosomal differential activity of the hybrids on different stages and strains of T. cruzi, the hybrids were first tested on trypomastigotes of the reference strain of T. cruzi, the CL Brener strain. In parallel, cytotoxicity was assayed on NRK cells, a cell line that we have used as an infection model in the past [11]. To this end, the trypomastigotes and NRK cells were incubated with increasing concentrations of the hybrids and the calculated $\mathrm{IC}_{50}$ values (Table 2). All the hybrids showed some degree of trypanosomal activity. In particular, eight compounds-including the peracetylated and non-acetylated forms of the quinidine/litocholic bile acid conjugate (4c and $5 \mathbf{c}$ ), the cinchonine/chenodeoxycholic bile acid conjugate (4f and $\mathbf{5 f}$ ), and the cinchonidine/litocholic bile acid conjugate (4g and $5 \mathbf{g}$ ), as well as the peracetylated form of the cinchonidine/chenodeoxycholic bile acid conjugate (4h) and the non-acetylated form of the cinchonin/litocholic bile acid (5e) — displayed $\mathrm{IC}_{50}$ values below $1 \mu \mathrm{g} / \mathrm{mL}$ and/or selectivity indices of greater than 10 (Table 2, in grey). 
Table 2. $\mathrm{IC}_{50}$ values for trypomastigotes and NRK cells were determined as described in Materials and Methods. The selectivity index (SI) was calculated as $\mathrm{IC}_{50} \mathrm{NRK} / \mathrm{IC}_{50}$ parasite. Hybrids with an $\mathrm{IC}_{50}$ close to $1 \mu \mathrm{g} / \mathrm{mL}$ and/or a selectivity higher then 10 (in grey) were selected as cytotoxic studies using other strains and for infection assays (see text). ND: Not Determined.

\begin{tabular}{cccc}
\hline & T. cruzi CL Brener & NRK Cells & Selectivity \\
\hline Hybrid & IC $_{\mathbf{5 0}}(\boldsymbol{\mu g} / \mathbf{m L})$ & IC $_{\mathbf{5 0}}(\boldsymbol{\mu g} / \mathbf{m L})$ & NRK/T. cruzi \\
\hline $5 \mathrm{~b}$ & $0.90 \pm 0.10$ & $5.10 \pm 0.76$ & 5.67 \\
\hline $4 \mathrm{~b}$ & $0.80 \pm 0.13$ & $3.91 \pm 0.29$ & 4.89 \\
\hline $5 \mathrm{a}$ & $3.71 \pm 0.13$ & $15.30 \pm 4.04$ & 4.12 \\
\hline $4 \mathrm{a}$ & $0.64 \pm 0.15$ & $1.41 \pm 0.13$ & 2.20 \\
\hline $5 \mathrm{~d}$ & $0.40 \pm 0.05$ & $1.59 \pm 0.54$ & 3.98 \\
\hline $4 \mathrm{~d}$ & $0.72 \pm 0.07$ & $3.30 \pm 0.08$ & 4.58 \\
\hline $5 \mathrm{c}$ & $0.78 \pm 0.11$ & $>11$ & $>10$ \\
\hline $4 \mathrm{c}$ & $1.08 \pm 0.23$ & $16.53 \pm 0.18$ & 15.30 \\
\hline $5 \mathrm{f}$ & $0.34 \pm 0.03$ & $4.02 \pm 0.55$ & 12.18 \\
\hline $4 \mathrm{f}$ & $0.51 \pm 0.06$ & $6.69 \pm 1.51$ & ND \\
\hline $5 \mathrm{e}$ & $3.96 \pm 2.69$ & $>30$ & 6.46 \\
\hline $4 \mathrm{e}$ & $1.16 \pm 0.15$ & $7.50 \pm 0.29$ & 2.23 \\
\hline $5 \mathrm{~h}$ & $0.30 \pm 0.00$ & $0.67 \pm 0.05$ & 9.28 \\
\hline $4 \mathrm{~h}$ & $0.70 \pm 0.18$ & $6.50 \pm 0.28$ & 10.58 \\
\hline $5 \mathrm{~g}$ & $2.56 \pm 0.58$ & $27.11 \pm 4.54$ & 9.46 \\
\hline $4 \mathrm{~g}$ & $1.30 \pm 0.01$ & $12.30 \pm 0.81$ & $\mathrm{ND}$ \\
\hline $\mathrm{Bz}$ & $2.5 \pm 0.01$ & $\mathrm{ND}$ &
\end{tabular}

Because of the high genetic variability and phenotypic diversity that T. cruzi presents, the parasite has been classified into six genetic groups (discrete typing units, DTUs) named TcI-TcVI [12]. The DTUs present different eco-epidemiological, clinical, and geographic associations, with several genetic molecular markers that are being used to classify the strains after their isolation from biological samples [12]. As a consequence of this variability, in vitro and in vivo differential drug susceptibility among strains has been reported [13-17]. Taking this into account, hybrids presenting an $\mathrm{IC}_{50} \leq 1 \mu \mathrm{g} / \mathrm{mL}$ and/or a selectivity index (SI) $\geq 10$ from the screening with CL Brener, were tested on trypomastigotes from the Y and the RA strains of T. cruzi (DTU II and VI, respectively) (Table 3). Trypomastigotes of the RA strain (DTU VI) showed a similar response to the treatment with the hybrids than those of the CL Brener strain, which is another member of the DTU VI. On the other hand, the Y strain (DTU II) was more resistant to the control drug, the commercial available Bz, and most of the assayed hybrids. However, the peracetylated and non-acetylated forms of the cinchonine/chenodeoxycholic bile acid conjugates $4 \mathbf{f}$ and $5 \mathbf{f}$ had $\mathrm{IC}_{50}$ values of 0.50 and $0.65 \mu \mathrm{g} / \mathrm{mL}$, respectively, against $\mathrm{Y}$ strain trypomastigotes. It is noteworthy that these results represented a 20-30-fold difference compared to the $\mathrm{IC}_{50}$ value of $\mathrm{Bz}$.

Not only the genetic diversity among strains should be taken into account while searching for new drugs. Differential susceptibility of the different life cycle stages of the parasite within the same strain [18] should be also considered. In this regard, Bz and $\mathrm{Nf}$ effectiveness against axenic epimastigotes and the intracellular stages of T. cruzi have been already reported [19]. Furthermore, drug sensitivity exhibited by the extracellular forms (i.e., epimastigotes and trypomastigotes) could sometimes be higher than the sensitivity of the intracellular form of the parasite, in part because of its intracellular availability [20] More importantly, given that in the chronic phase of Chagas disease, current chemotherapy is not efficient and that parasitemia is usually low, performing new drug screenings on the intracellular replicative stage of the parasite appears to be the better approach. To confirm their anti-parasitic activity, nine of the hybrids were evaluated against intracellular amastigotes of the $Y$ strain at the $\mathrm{IC}_{50}$ found for trypomastigotes of the same strain. Briefly, trypomastigotes were incubated with NRK cells and left to infect for two hours. After the infection period, free trypomastigotes were removed from the medium, monolayers were washed, and media containing the final concentration of the drug 
were added. Forty-eight hours post infection, cells were fixed and stained, and amastigotes/100 cells were calculated. As shown in Figure 1A,B, a significant reduction in intracellular amastigotes was observed for the hybrids $\mathbf{4 f}$ and $\mathbf{5 f}$ compared to untreated infected cells.

Table 3. Hybrid $\mathrm{IC}_{50}$ values for T. cruzi tripomastigote strains from different discrete typing units (DTUs).

\begin{tabular}{ccc}
\hline & T. cruzi RA (DTU VI) & T. cruzi Y (DTU II) \\
\hline Hybrid & IC $_{\mathbf{5 0}}(\boldsymbol{\mu g} / \mathbf{m L})$ & IC $_{\mathbf{5 0}}(\boldsymbol{\mu g} / \mathbf{m L})$ \\
\hline $5 \mathrm{c}$ & $0.79 \pm 0.19$ & $\geq 2.00$ \\
\hline $4 \mathrm{c}$ & $\mathrm{ND}$ & $\geq 1.00$ \\
\hline $5 \mathrm{f}$ & $0.31 \pm 0.10$ & $0.65 \pm 0.07$ \\
\hline $4 \mathrm{f}$ & $0.25 \pm 0.10$ & $0.50 \pm 0.03$ \\
\hline $4 \mathrm{~h}$ & $1.50 \pm 0.50$ & $\geq 2.00$ \\
\hline $5 \mathrm{~g}$ & $3.03 \pm 0.24$ & $3.25 \pm 0.67$ \\
\hline $4 \mathrm{~g}$ & $1.10 \pm 0.21$ & $3.05 \pm 0.71$ \\
\hline $\mathrm{Bz}$ & $2.5 \pm 0.32$ & $\geq 15.00$ \\
\hline
\end{tabular}

A

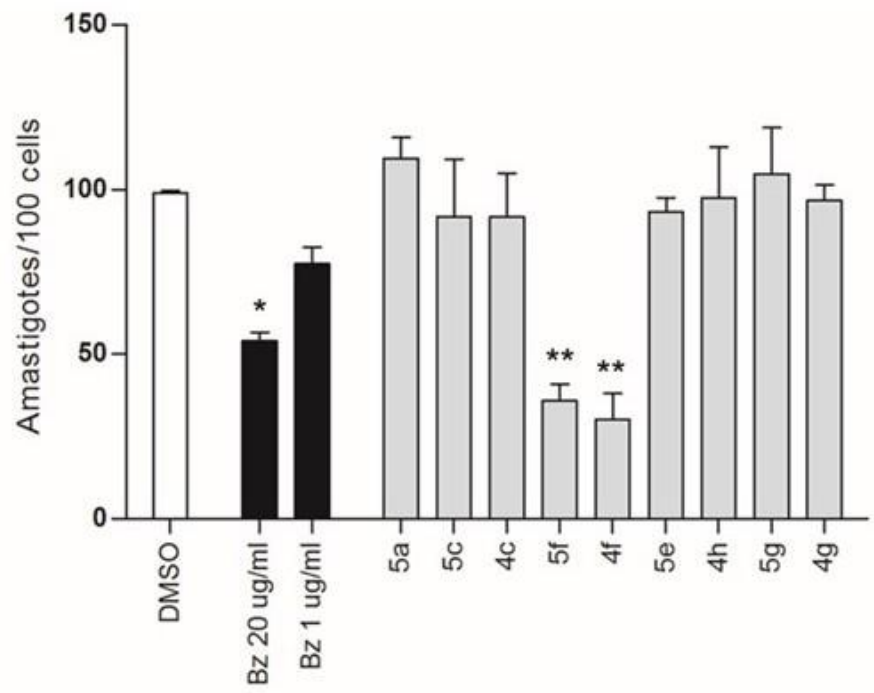

B
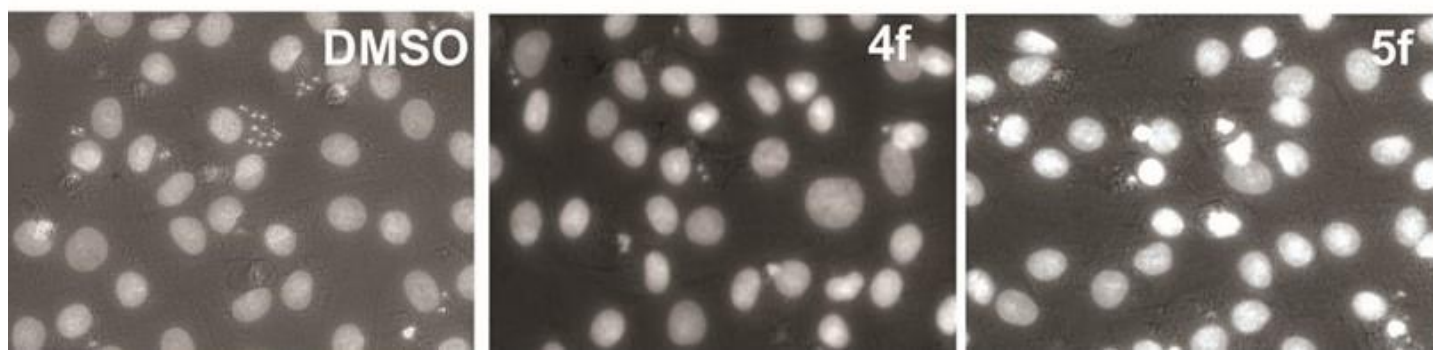

Figure 1. (A) Effects of hybrids on intracellular amastigotes. Hybrids were evaluated at the estimated parasite $\mathrm{IC}_{50}$ concentration for the $\mathrm{Y}$ strain (Table 3). Bars indicate mean $\pm \mathrm{SE}$ of at least three independent assays (see Methods). ${ }^{*} p<0.05,{ }^{* *} p<0.01$. (B) Representative microscope photographs of NRK infected cells treated as indicated. 
To fully eliminate the intracellular parasite, a trypanocidal drug action is ideally desired. For trypanostatic drugs, a longer chemotherapy is required to allow the elimination of the intracellular parasite, since the anti-parasitic effect could be reversed upon removal of the drug. In order to characterize the antiparasitic features of the hybrids, our strategy was to remove the hybrids from the medium of infected NRK cells and let the infection develop. In this approach, after the two hour infection of NRK cells with trypomastigotes of the Y strain, compounds were added and left for 72 hours before being replaced with fresh medium without drugs. Six days post infection, the trypomastigotes released to the supernatant were quantified. Two different scenarios were expected: 1) Upon removal of a trypanostatic hybrid, intracellular amastigotes would proliferate, and a higher trypomastigote release, close to control with no hybrid, would be observed; or 2) the hybrids would have a trypanocidal effect and non-viable amastigotes would not be able to proliferate, so the trypomastigote count would decrease. The results from Figure 2 clearly indicate that amastigotes could not recover from the 72 hours of treatment with hybrids $\mathbf{5 f}$ and $\mathbf{4 f}$, since the trypomastigote count in the supernatant of infected cells was significantly lower than non-treated control.

A

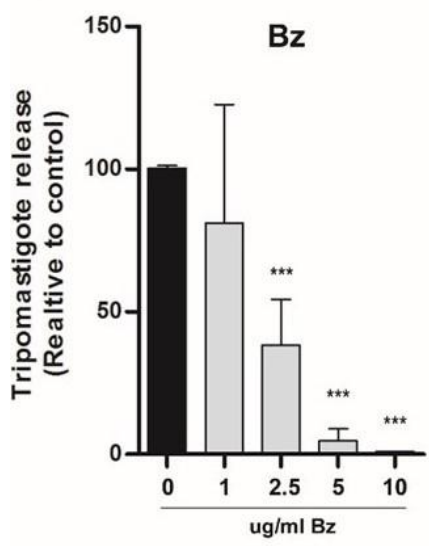

B

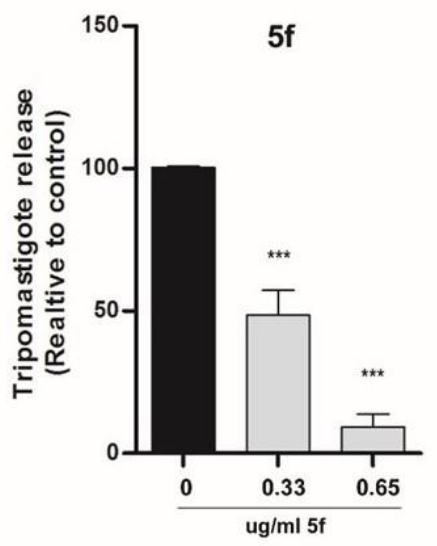

C

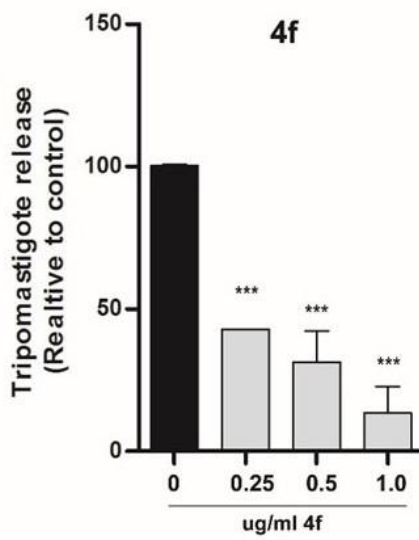

Figure 2. Hybrid activity on trypomastigote release at day six post infection. Cells treated with the indicated concentration of benznidazol (A) or the hybrids compounds $5 \mathbf{f}(\mathbf{B})$ or $\mathbf{4 f}(\mathbf{C})$. Bars indicate mean \pm ES of at least three independent assays (see Methods) ${ }^{* * *} p<0.001$.

Overall, the results obtained with hybrids $\mathbf{4 f}$ and $\mathbf{5 f}$ are promising. These hybrids shown to be active against amastigotes of the $\mathrm{Y}$ strain, presenting a lower $\mathrm{IC}_{50}$ than $\mathrm{Bz}$ (Figure 1) and this anti-parasitic action could not reverse upon removal of the hybrids (Figure 2).

\section{Discussion}

An alternative approach to the discovery of new drugs to treat old neglected diseases, such as trypanosomiasis, could be the synthesis of new bioactive compounds through hybridization. In particular, the synthesis of hybrids of bioactive compounds that combine the properties of their individual components has emerged as a fast growing methodology in medicinal chemistry $[5,10,21]$. Following the strategy of combining the anti-parasitic properties of natural Cinchona alkaloids with the known properties of bile acids as drug transporters, a series of 16 hybrids of Cinchona alkaloids and bile acids were prepared via a Barton-Zard decarboxylation reaction. It was previously shown that these hybrids have anti-plasmodial and anti-trypanosomal activity [10]. In addition to these results, in this work, we have shown the promising trypanocidal activity of the hybrids against trypomastigotes of different DTUs of T. cruzi, such as CL Brener, RA, and Y. The high genetic variability and phenotypic diversity among strains of $T$. cruzi can lead to differential susceptibilities to drugs, suggesting that a broader screening, including different strains from different DTUs, should be performed in the search of new therapeutic drugs. In fact, we observed that the trypomastigotes of the $Y$ strain were more resistant than the trypomastigotes of the CL Brener and RA strains to Bz and most of the newly 
synthetized hybrids. However, hybrids $\mathbf{4 f}$ and $\mathbf{5 f}$ presented a strong activity against trypomastigotes of the Y strain, as well. More importantly, a significant anti-parasite activity was found when these hybrids were tested on Y strain amastigotes, the intracellular proliferative stage of the parasite. This activity was reflected in a significant reduction in the number of intracellular amastigotes per infected cell. In addition, the action of hybrids $\mathbf{4} \mathbf{f}$ and $\mathbf{5 f}$ appeared to be trypanocidal, since amastigotes could not recover to proliferate and differentiate when the infection was left to develop. This fact that was reflected in a decreased in the number free trypomastigotes in the supernatant of infected cells after removal of the hybrids.

\section{Materials and Methods}

\subsection{Cells and Parasites}

The NRK and Vero cell lines were routinely maintained in DMEM (Gibco) supplemented with 10\% SFB (Natocor) and Penicillin/Streptomicin (100 Units $/ 0.1 \mathrm{mg} / \mathrm{mL}$, Sigma) at $37^{\circ} \mathrm{C}$ and $5 \% \mathrm{CO}_{2}$ atmosphere. The trypomatigotes of T. cruzi strains CL Brener, Y, and RA were routinely maintained in Vero cells cultured in DMEM supplemented with 4\% SFB and Penicillin/Streptomicin. The trypomastigotes of each strain were purified from infected Vero cells supernatants and used in the different assays.

\subsection{Parasite $I_{50}$ Estimation}

$2 \times 10^{6} / \mathrm{mL}$ trypomastigotes were incubated with different concentrations of the hybrids, control drug or vehicle, by triplicate at $37^{\circ} \mathrm{C}$ and $5 \% \mathrm{CO}_{2}$ for $24 \mathrm{~h}$. Next, trypomastigotes were counted in a Neubauer chamber. The $\mathrm{IC}_{50} \pm \mathrm{SD}(\mathrm{n}=3)$ were estimated using the "Dose-Response" module in Graphpad Prism.

\subsection{Cells $I C_{50}$ Estimation}

$1 \times 10^{5} / \mathrm{mL}$ NRK cells were grown overnight in a 96 multi-well plate. The culture medium was replaced by a culture medium containing increasing concentrations of hybrids, control drugs or vehicles, and cells incubated at $37^{\circ} \mathrm{C}$ and $5 \% \mathrm{CO}_{2}$ for $48 \mathrm{~h}$. Next, cells were washed, fixed for $10 \mathrm{~min}$ with cold methanol (Sintorgan), and stained with violet crystal (Sigma 0.5\% in methanol). After an exhaustive wash, cells were dried overnight. 10\% acetic acid (Biopack) was added to each well, and the absorbance measured at $600 \mathrm{~nm}$. Similarly, a standard curve was prepared (absorbance vs. increasing concentrations of NRK cells) to estimate the NRK IC 50 using Graphpad Prism.

\subsection{Amastigote Count}

Infections were performed as previously described [11]. Briefly, NRK cells (growing on glass slides in a 24 multi-well plate) were infected for $2 \mathrm{~h}$ with trypomastigotes of the $\mathrm{Y}$ strain. After extensive washing, a medium containing compounds at the corresponding trypomastigote $\mathrm{IC}_{50}$ concentration (see Table 1) was added. After $48 \mathrm{~h}$ of incubation, cells were fixed with $4 \%$ formalin, stained with DAPI and photographed in a fluorescence microscope (Olympus). The amastigotes/100 cells were determined counting 1000 cells from each well (3000 cells/compound) using the ImageJ cell counter plugin.

\subsection{Trypomastigote Release Assay}

NRK cells were cultured and treated as described in Section 4.1. At day 3 post infection (pi), the medium with hybrids was replaced by fresh media (with $4 \%$ SFB). At day 6 pi, the released trypomastigotes in the supernatant of infected were counted using a Neubauer chamber.

\subsection{Statistics}

In all cases, 3 independent experiments were done by triplicate. In amastigotes count and trypomastigotes released from infected cells, the results are presented as normalized relative to control 
without drug. The mean \pm SD of amastigotes/100 cells or trypomastigote released were calculated and analyzed with one-way ANOVA with Dunnett posttest performed with Graphpad Prism software.

Author Contributions: Conceptualization, D.M., A.L., J.A.P. and M.M.E.; methodology, D.M. and M.M.E.; software, D.M.; validation, D.M., D.B. and G.F.; formal analysis, D.M. and M.M.E.; investigation, D.M., D.B. and G.F.; resources, J.A.P. and M.M.E.; data curation, D.M.; writing-original draft preparation, D.M., J.A.P. and M.M.E.; writing-review and editing, D.M., J.A.P. and M.M.E.; visualization, D.M. and M.M.E.; supervision, M.M.E.; project administration, M.M.E.; funding acquisition, M.M.E.

Funding: This work was partially supported by the grant PICT-2015-1713 of the Agencia Nacional de Promoción Científica y Tecnológica (ANPCyT, Argentina) to MME. MME and JP are members of the Research Career of the Consejo Nacional de Investigaciones Científicas y Técnicas (CONICET). GF are CONICET Research Fellow. DB is a fellow of the Programa Nacional de Becas de Posgrado en el Exterior “Don Carlos Antonio López" (República del Paraguay).

Conflicts of Interest: The authors declare no conflicts of interest.

\section{References}

1. Lechuga, G.C.; Borges, J.C.; Calvet, C.M.; de Araujo, H.P.; Zuma, A.A.; do Nascimento, S.B.; Motta, M.C.M.; Bernardino, A.M.R.; Pereira, M.C.S.; Bourguignon, S.C. Interactions between 4-aminoquinoline and heme: Promising mechanism against Trypanosoma cruzi. Int. J. Parasitol. 2016, 6, 154-164. [CrossRef] [PubMed]

2. Kinnamon, K.E.; Poon, B.T.; Hanson, W.L.; Waits, V.B. Primaquine analogues that are potent anti-Trypanosoma cruzi agents in a mouse model. Ann. Trop. Med. Parasitol. 1996, 90, 467-474. [CrossRef] [PubMed]

3. Foley, M.; Tilley, L. Quinoline antimalarials: Mechanisms of action and resistance and prospects for new agents. Pharmacol. Ther. 1998, 79, 55-87. [CrossRef]

4. Tiuman, T.S.; Santos, A.O.; Ueda-Nakamura, T.; Filho, B.P.; Nakamura, C.V. Recent advances in leishmaniasis treatment. Int. J. Infect. Dis. 2011, 15, 525-532. [CrossRef] [PubMed]

5. Kacprzak, K.; Ruszkowski, P.; Valentini, L.; Huczynski, A.; Steverding, D. Cytotoxic and trypanocidal activities of Cinchona alkaloid derivatives. Chem. Biol. Drug Des. 2018, 92, 1778-1787. [CrossRef] [PubMed]

6. Fakhfakh, M.A.; Fournet, A.; Prina, E.; Mouscadet, J.F.; Franck, X.; Hocquemiller, R.; Figadere, B. Synthesis and biological evaluation of substituted quinolines: Potential treatment of protozoal and retroviral co-infections. Bioorganic Med. Chem. 2003, 11, 5013-5023. [CrossRef]

7. Kacprzak, K.M. Chemistry and Biology of Cinchona Alkaloids. In Natural Products: Phytochemistry, Botany and Metabolism of Alkaloids, Phenolics and Terpenes; Ramawat, K.G., Mérillon, J.-M., Eds.; Springer: Berlin/Heidelberg, Germany, 2013; pp. 605-641.

8. Pranay, G.; Puspal, D. Spectrum of biological properties of Cinchona alkaloids: A brief review. J. Pharmacogn. Phytochem. 2017, 6, 162-166.

9. Dawson, P.A. Role of the intestinal bile acid transporters in bile acid and drug disposition. Handb. Exp. Pharmacol. 2011, 201, 169-203.

10. Leverrier, A.; Bero, J.; Frederich, M.; Quetin-Leclercq, J.; Palermo, J. Antiparasitic hybrids of Cinchona alkaloids and bile acids. Eur. J. Med. Chem. 2013, 66, 355-363. [CrossRef] [PubMed]

11. Musikant, D.; Ferri, G.; Durante, I.M.; Buscaglia, C.A.; Altschuler, D.L.; Edreira, M.M. Host Epac1 is required for cAMP-mediated invasion by Trypanosoma cruzi. Mol. Biochem. Parasitol. 2017, 211, 67-70. [CrossRef] [PubMed]

12. Zingales, B.; Andrade, S.G.; Briones, M.R.; Campbell, D.A.; Chiari, E.; Fernandes, O.; Guhl, F.; Lages-Silva, E.; Macedo, A.M.; Machado, C.R.; et al. A new consensus for Trypanosoma cruzi intraspecific nomenclature: Second revision meeting recommends TcI to TcVI. Memorias do Instituto Oswaldo Cruz 2009, 104, 1051-1054. [CrossRef] [PubMed]

13. Moreno, M.; D’Avila, D.A.; Silva, M.N.; Galvao, L.M.; Macedo, A.M.; Chiari, E.; Gontijo, E.D.; Zingales, B. Trypanosoma cruzi benznidazole susceptibility in vitro does not predict the therapeutic outcome of human Chagas disease. Memorias do Instituto Oswaldo Cruz 2010, 105, 918-924. [CrossRef] [PubMed]

14. Villarreal, D.; Barnabe, C.; Sereno, D.; Tibayrenc, M. Lack of correlation between in vitro susceptibility to Benznidazole and phylogenetic diversity of Trypanosoma cruzi, the agent of Chagas disease. Exp. Parasitol. 2004, 108, 24-31. [CrossRef] [PubMed] 
15. Toledo, M.J.; Bahia, M.T.; Carneiro, C.M.; Martins-Filho, O.A.; Tibayrenc, M.; Barnabe, C.; Tafuri, W.L.; de Lana, M. Chemotherapy with benznidazole and itraconazole for mice infected with different Trypanosoma cruzi clonal genotypes. Antimicrob. Agents Chemother. 2003, 47, 223-230. [CrossRef] [PubMed]

16. Murta, S.M.; Gazzinelli, R.T.; Brener, Z.; Romanha, A.J. Molecular characterization of susceptible and naturally resistant strains of Trypanosoma cruzi to benznidazole and nifurtimox. Mol. Biochem. Parasitol. 1998, 93, 203-214. [CrossRef]

17. Filardi, L.S.; Brener, Z. Susceptibility and natural resistance of Trypanosoma cruzi strains to drugs used clinically in Chagas disease. Trans. R. Soc. Trop. Med. Hyg. 1987, 81, 755-759. [CrossRef]

18. Zingales, B.; Miles, M.A.; Moraes, C.B.; Luquetti, A.; Guhl, F.; Schijman, A.G.; Ribeiro, I. Drug discovery for Chagas disease should consider Trypanosoma cruzi strain diversity. Memorias do Instituto Oswaldo Cruz 2014, 109, 828-833. [CrossRef] [PubMed]

19. Quebrada Palacio, L.P.; Gonzalez, M.N.; Hernandez-Vasquez, Y.; Perrone, A.E.; Parodi-Talice, A.; Bua, J.; Postan, M. Phenotypic diversity and drug susceptibility of Trypanosoma cruzi TcV clinical isolates. PLoS ONE 2018, 13, e0203462. [CrossRef] [PubMed]

20. Fonseca-Berzal, C.; Aran, V.J.; Escario, J.A.; Gomez-Barrio, A. Experimental models in Chagas disease: A review of the methodologies applied for screening compounds against Trypanosoma cruzi. Parasitol. Res. 2018, 117, 3367-3380. [CrossRef] [PubMed]

21. Leverrier, A.; Bero, J.; Cabrera, J.; Frederich, M.; Quetin-Leclercq, J.; Palermo, J.A. Structure-activity relationship of hybrids of Cinchona alkaloids and bile acids with in vitro antiplasmodial and antitrypanosomal activities. Eur. J. Med. Chem. 2015, 100, 10-17. [CrossRef] [PubMed]

Sample Availability: Samples of the compounds $\mathbf{4 f}$ and $\mathbf{5 f}$ are available from the authors.

(C) 2019 by the authors. Licensee MDPI, Basel, Switzerland. This article is an open access article distributed under the terms and conditions of the Creative Commons Attribution (CC BY) license (http://creativecommons.org/licenses/by/4.0/). 